\begin{tabular}{lll} 
Available online at www.iponlinejournal.com \\
\hline
\end{tabular}

\title{
Correction of skeletal class II malocclusion using class II elastics in an adolescent patient
}

\author{
Mayank Trivedi ${ }^{*}$, Raghunath $\mathbf{N}^{2}$, Alekya Akasapu ${ }^{3}$ \\ ${ }^{1}$ Senior Lecturer, ${ }^{2}$ Professor and Head, ${ }^{3}$ Registrar(Consultant Oral Pathologist), ${ }^{1,2}$ Dept. of Orthodontics and Dentofacial Orthopedics, \\ ${ }^{1}$ Rajarajeshwari Dental College and Hospital, Bangalore, Karnataka, ${ }^{\mathbf{2} J S S}$ Dental College and Hospital, Mysore, Karnataka, India, ${ }^{\mathbf{3}}$ Private \\ Dental Clinic, Kuwait
}

\begin{abstract}
Application of elastics in orthodontics has various outcomes in relation to maxillary arch, mandibular arch, facial pattern and occlusal plane. All these factors can be modified depending upon the response of the individual towards the treatment procedure. Elastics being a dependable mode of changing such parameters have been employed in orthodontics from time to time. In the present case report class II elastics were incorporated with a motive to stimulate growth and change or improve the facial profile as the individual was in a growing phase. With continuous application of elastics and patient cooperation satisfactory occlusion and facial profile was achieved for the patient.
\end{abstract}

Keywords: Class II malocclusion, Class II elastics, Growth, Profile.

\section{Introduction}

Evaluation and prediction of growth is an important prerequisite for assessing the remaining growth of an individual. Orthodontic treatment is mainly sort by the adult class of patients but it is always the best when growth is utilized by intervention during the adolescent phase of patient growth. ${ }^{1}$ Response of an individual to growth modification is very subjective because few individuals respond better to treatment as they are early or late growers with considerable variations in the growth spurts respectively. ${ }^{2}$ Assessing growth and favourably utilizing it is very difficult as it is important to keep a track on the ossification or growth status in an individual, in other words an operator should be able to diagnose and implicate treatment at the right time as it takes place at different chronological ages. Radiographs that can be put to use are hand wrist radiograph which provides with essentials of anatomy and ossification status, lateral cephalogram provides with information regarding the maturation status in cervical vertebrae and sinuses, OPG may be useful for predicting the growth status as per the level of maturation or calcification in mandibular canine region and overall dental maturation along with intraoral periapical radiograph. ${ }^{3}$

Correction of class II malocclusion with class II elastics is considered as one of the key support along with fixed orthodontic appliance in growing patients. Having been incorporated and stretched between the incisor and canine region in the maxillary arch and the erupted second molar in the mandibular arch (as used in the present case report) among the rigid arch wires is said to decrease the vertical component of force by about $27 \%$ to $20 \%$ and increases the horizontal component of force in the range which may be favourable for a vertically growing individual. An advice to the patient for wearing on a day to day basis is said to be helpful as both the vertical and horizontal components of force are in equilibrium and preferably in 50-300 grams range. ${ }^{4}$ Along with mandibular skeletal advancement other important function that can be achieved with class II elastics are labial buccal tipping of the mandibular incisors, opening of the bite and correction of the midline. ${ }^{5}$

Skeletal changes are bought by judicious use of elastics particularly for a longer period of time on a 24 hour basis and can be used for correction of class II malocclusion without any significant side effects. ${ }^{6}$ Hence with such application of elastics a satisfactory correction of class II malocclusion and canine relation with acceptable facial profile was achieved. The main aim and objective of this case report is to substantiate that elastics when used during the growth period can bring about orthopaedic changes.

\section{Diagnosis and treatment plan}

A 12 year old male patient came to the department of orthodontics and dentofacial orthopaedics, JSS dental college and hospital, Mysore, India, and desired to get his teeth corrected. After extraoral examination, patient presented with Angle's Class II division 1 malocclusion with incompetent lips, facial form was mesoprosopic, shape of head mesocephalic and convex profile. After intraoral examination, patient presented with crowding and proclination in the upper and lower anterior teeth with class II canine, class II molar relation and presence of symmetrical generalized linear enamel hypoplasia depicting ring like appearance on buccal and lingual surfaces formed as a result of enamel maturation defect(figure 1). Fixed orthodontic treatment was started and after initial levelling and aligning patient was put on rigid archwires and class II elastics were employed. Total duration of treatment was 2 years and one month, out of which initial levelling and aligning was performed for about eight-month time. Class II elastics were employed for a total of seventeen months after

*Corresponding Author: Mayank Trivedi, Dept. of Orthodontics and Dentofacial Orthopedics, Rajarajeshwari Dental College and Hospital, Bangalore, Karnataka, India

Email: 1987.mayank@gmail.com

http://doi.org/10.18231/j.ijodr.2019.021 
which class I canine and molar relation were achieved with a significant improvement of profile with reduction in overjet, overbite, lip incompetency along with matching midlines. Patient was satisfied with the overall outcome of the treatment.

\section{Treatment progress}

As the extraoral and intraoral examination was completed the patient was evaluated for the status of growth. Radiographs which were advised for the patient consisted of hand wrist radiographs, lateral cephalogram and orthopantomogram (OPG). After careful observation of the hand wrist radiograph it was interpreted that the patient was still in the $3^{\text {rd }}$ stage of growth and development with absence of ulnar sesamoid which is the progressive stage of ossification according to Bjork, Grave and Brown method of growth assessment. The $3^{\text {rd }}$ stage presents with further three sub-stages characterised by the appearance of hamular process of hamate exhibiting ossification, ossification of pisiform and the epiphysis and diaphysis of radius being equal, the latter was not perceived yet the former two stages were evident showing presence of $75 \%$ remaining growth. On interpreting the lateral cephalogram for cervical vertebrae maturation index it showed a stage of acceleration exhibiting $65 \%$ to $85 \%$ of the growth remaining and it was also discovered that the patient was a vertically growing individual. Lastly the presence of " $G$ " stage of tooth mineralization with respect to Demirjian index showed parallel walls of the root canal with apical end partially open and in molar root only distal end part is rated with same characteristic appearance (Fig. 2). Special consideration was given to the etching of the enamel surface by prolonging the etching time as in cases of enamel hypoplasia with enamel maturation defects the etching patterns or resin tags are difficult to obtain to an extent because of less surface roughness and less retention. Case was bonded using 0.22 " MBT prescription. Initial levelling and aligning was done using NiTi wire in the sequence of 0.12 ", 0.14 ", 0.16 " and 0.18 ". 0.18" AJ Wilcock wires in upper and lower arches were used, upper arch NiTi open coil spring was used with AJ Wilcock wire for creating space to correct the instanding lateral incisor (12). As the alignment in both arches were achieved, $17 \times 25$ " thermal NiTi wires were used prior to stainless steel archwires. Before placing class II elastics, $19 \times 25$ " stainless steel wires were placed for a visit prior to engaging class II elastics. After achieving class I canine and molar relation and discontinuing class II elastics, 17 25 " TMA wire was incorporated onto the maxillary arch for desired labial root torqueing of the in-standing lateral incisor (21). Bracket repositioning was done wherever correction was required with respect to the inclination of the roots. Settling elastics were placed and brackets were debonded (Fig. 3 and 4). After debonding, patient was put on fixed permanent lingual retainers along with Hawley's removable retainers in both upper and lower arches which he was instructed to maintain post completion of the fixed orthodontic treatment (Fig. 5).

\section{Treatment Results}

After levelling and aligning of upper and lower teeth (inclusive of class II mandibular canine and molar relation correction and settling) within a period of approximately twenty five months, patient achieved good facial profile with competent lips (Fig. 5). Post treatment lateral cephalogram and OPG were used for post treatment cephalometric finding and for doing a detailed cephalometric superimposition (figure 6). Post treatment findings included significant changes in the skeletal facial parameters from the pre-treatment values. Skeletal parameters which showed significant changes were mandibular values with changes in SNB angle from $72^{\circ}$ to $77^{\circ}$, ANB angle from $6^{\circ}$ to $3^{\circ}$, Go-Gn to $\mathrm{Sn}$ angle from $38.5^{\circ}$ to $36^{\circ}$, facial axis angle changed from $-7^{\circ}$ to $5^{\circ}$, lower anterior face height increased from $60 \mathrm{~mm}$ to $68 \mathrm{~mm}$, face height ratio increased from $58.8 \%$ to $71.80 \%$, effective mandibular length increased from $96 \mathrm{~mm}$ to $100 \mathrm{~mm}$, maxillary skeletal value showed deviation in the SNA parameter that was shifted from $78^{\circ}$ to $80^{\circ}$. Dental parameters that changed were slight retroclination of the upper incisors and proclination of the lower incisors and interincisal angle changed from previous of $104^{\circ}$ to $114^{\circ}$ (Fig. 6). Post-treatment dental models and photographs were put for comparison with the pre-treatment models and photographs respectively in order to appreciate the changes made to the patient's profile (fig. 7 and 8).

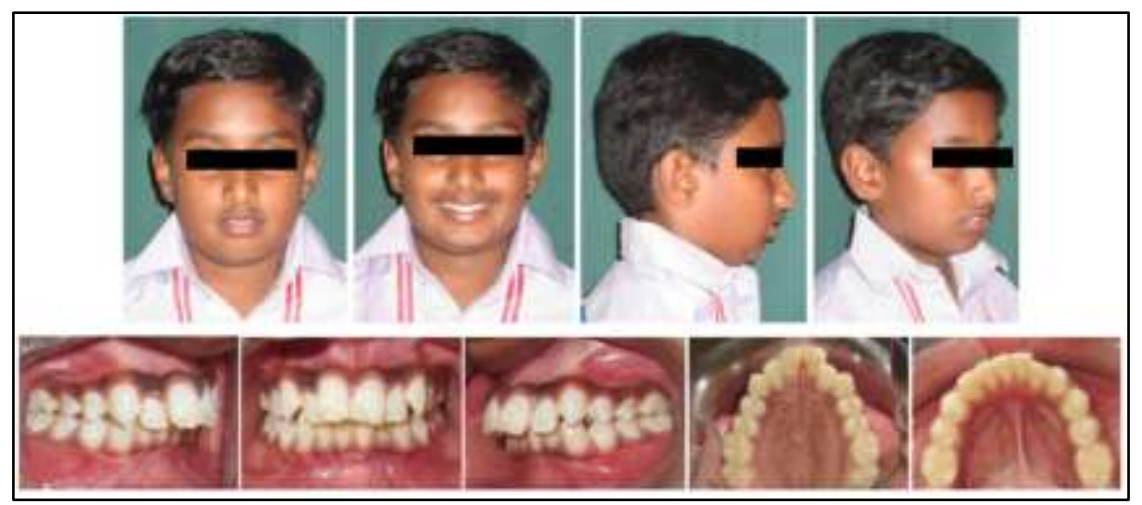

Fig. 1: Pre-Treatment extraoral and intraoral photographs 


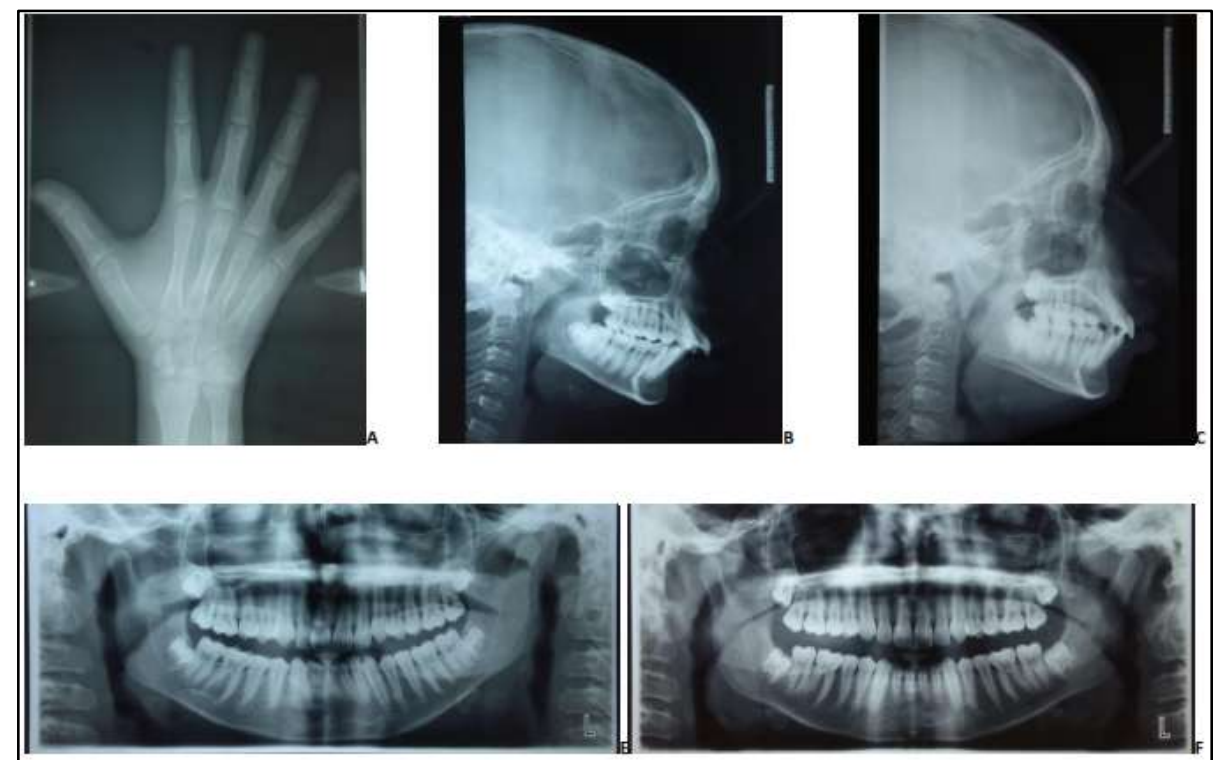

Fig. 2: Pre-Treatment hand wrist radiograph, B \& C-pre and post treatment lateral cephalogram, D and E pre and post treatment OPG
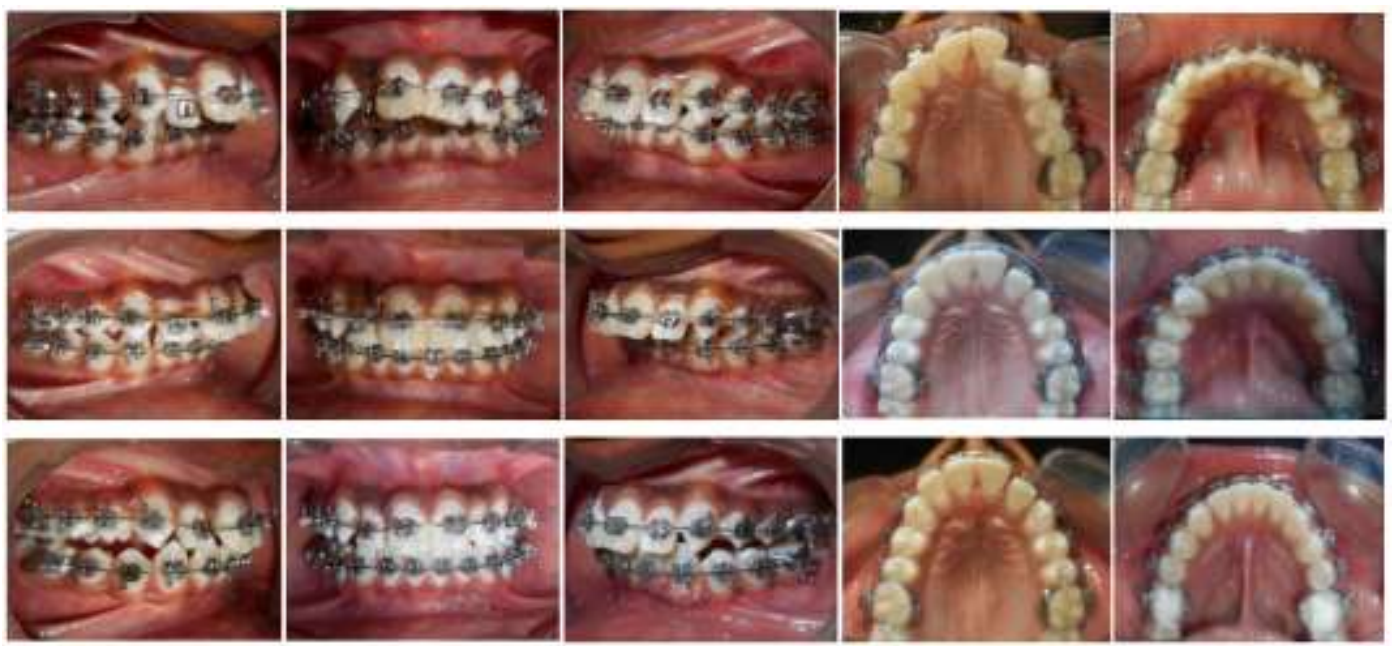

Fig. 3: Initial stages of archwires including correction of in-standing lateral incisors using NITI coil spring
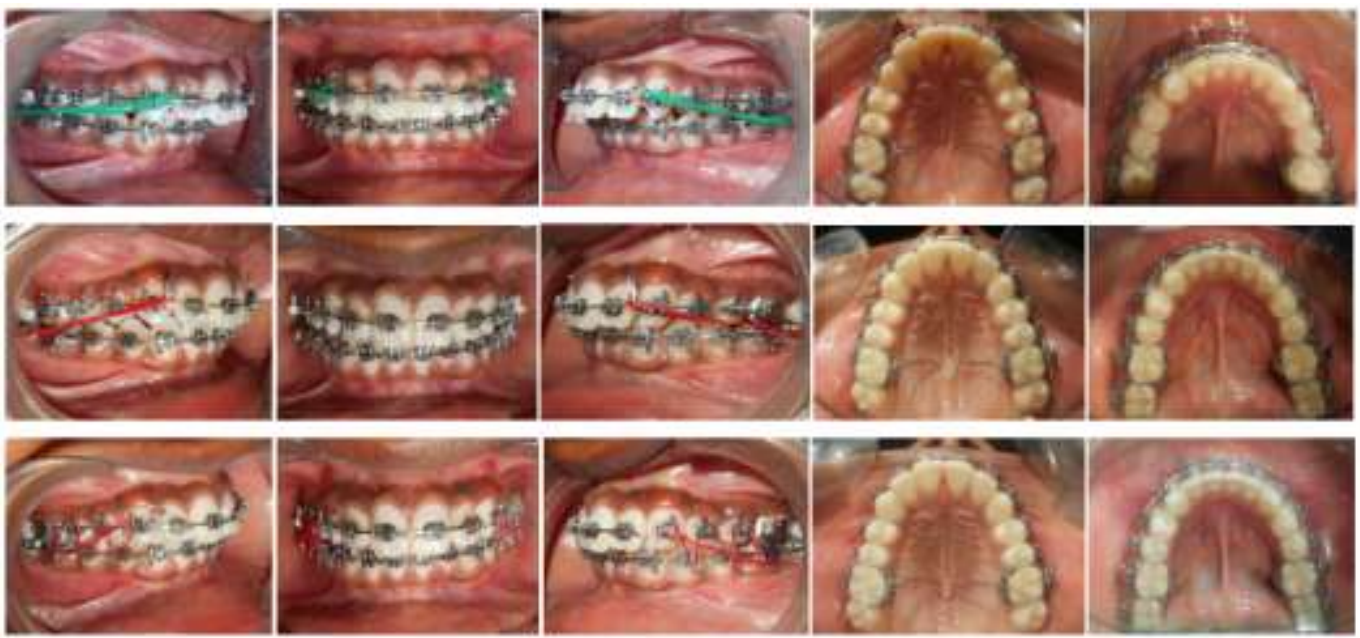

Fig. 4: Upper and lower arch on 19X25" stainless steel with elastics for class II correction and settling 


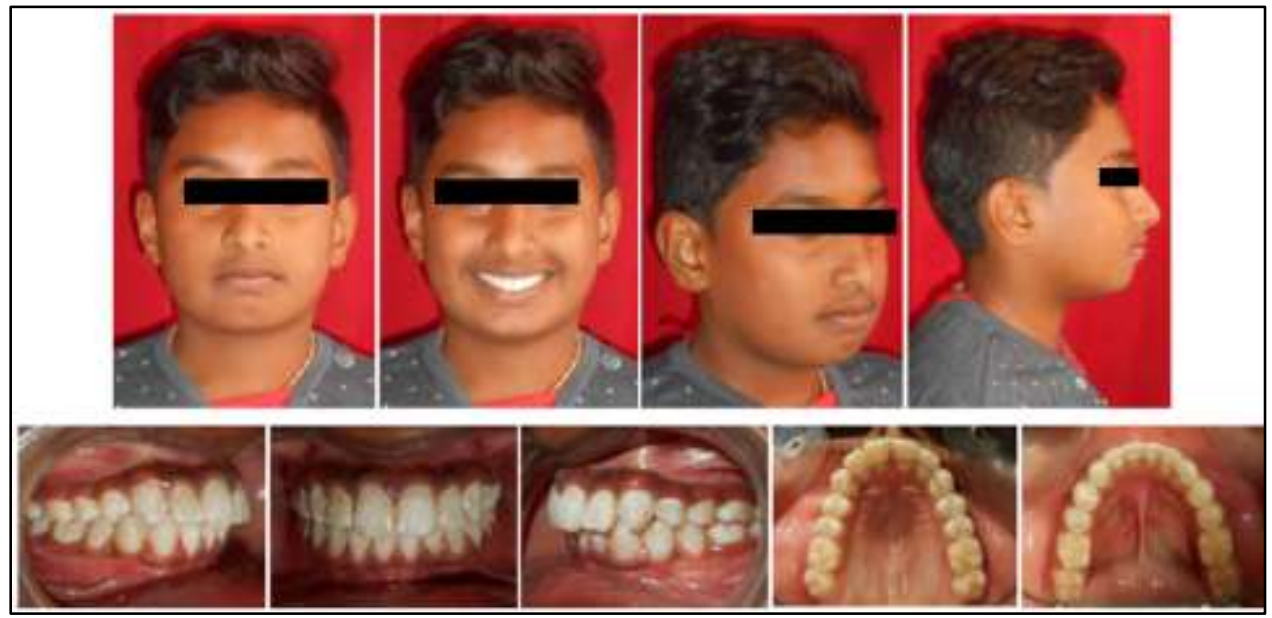

Fig. 5: Post-Treatment extraoral and intraoral photographs
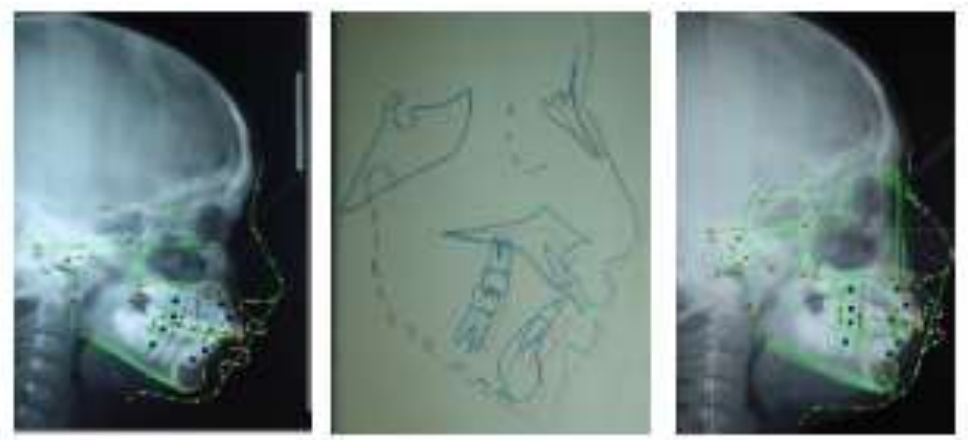

\begin{tabular}{|c|c|c|c|}
\hline VARIABLE & NORMAL & PRE TREATMENT & POST TREATMENT \\
\hline SNA & $82^{\circ} \pm 3$ & $78^{\circ}$ & $80^{\circ}$ \\
\hline SNB & $80^{\circ} \pm 3$ & $72^{\circ}$ & $77^{*}$ \\
\hline ANB & $3^{*} \pm 1$ & $6^{\circ}$ & $3^{*}$ \\
\hline WITTS APPRAISAL & $0 \mathrm{~mm}$ & $\begin{array}{l}\text { AO AHEAD OF } \\
\text { BO BY } 2.5 \mathrm{~mm}\end{array}$ & $\begin{array}{l}\text { BO AHEAD OF AO } \\
\text { BY } 1 \mathrm{~mm}\end{array}$ \\
\hline N $\perp$ POINT A & $0 \pm 2$ & $-7 \mathrm{~mm}$ & $-4 \mathrm{~mm}$ \\
\hline $\begin{array}{l}\text { N } \perp \text { POINT } \\
\text { POGONION }\end{array}$ & O TO $-4 \mathrm{~mm}$ & $-22 \mathrm{~mm}$ & $-14 \mathrm{~mm}$ \\
\hline $\begin{array}{l}\text { ANGLE OF } \\
\text { INCLINATION }\end{array}$ & $85^{\circ}$ & $90.5^{\circ}$ & $81 *$ \\
\hline GO-GN TO SN & $32^{\circ}$ & $38.5^{\circ}$ & $36^{\circ}$ \\
\hline EFF, MAX. LENGTH & $92.1 \pm 2.7$ & $80 \mathrm{~mm}$ & $80 \mathrm{~mm}$ \\
\hline $\begin{array}{l}\text { EFF. MAND. } \\
\text { LENGTH }\end{array}$ & $118.9 \pm 5$ & $96 \mathrm{~mm}$ & $100 \mathrm{~mm}$ \\
\hline$\checkmark$ AXIS & $66^{\circ}$ & $73^{\circ}$ & $68^{\circ}$ \\
\hline FACIAL AXIS & $0^{*}$ & $-7^{\circ}$ & $5^{\circ}$ \\
\hline UPPER INCISOR - NA & $4 \mathrm{~mm}$ & $7 \mathrm{~mm}$ & $6 \mathrm{~mm}$ \\
\hline UPPER INCISOR - NA & $22^{\circ}$ & $36^{*}$ & $24^{\circ}$ \\
\hline UPPER INCISOR - SN & $102^{\circ} \pm 2$ & $104^{\circ}$ & $103^{\circ}$ \\
\hline $\begin{array}{l}\text { UPPER INCISOR TO } \\
\text { MAXI. PLANE } \\
\text { ANGLE }\end{array}$ & $108^{*} \pm 5$ & $127^{\circ}$ & $120^{\circ}$ \\
\hline $\begin{array}{l}\text { LOWER INCISOR TO } \\
\text { MAND. PLANE } \\
\text { ANGLE }\end{array}$ & $92^{\circ} \pm 5$ & $100^{\circ}$ & $103^{*}$ \\
\hline $\begin{array}{l}\text { LOWER INCISOR - } \\
\text { NB }\end{array}$ & $4 \mathrm{~mm}$ & $6 \mathrm{~mm}$ & $8 \mathrm{~mm}$ \\
\hline $\begin{array}{l}\text { LOWER INCISOR - } \\
\text { NB }\end{array}$ & $25^{\circ}$ & $34^{\circ}$ & $37^{\circ}$ \\
\hline $\begin{array}{l}\text { INTER INCISAL } \\
\text { ANGLE }\end{array}$ & $133^{*} \pm 10$ & $104^{\circ}$ & $114^{\circ}$ \\
\hline $\begin{array}{l}\text { MAXI. - MAND. } \\
\text { PLANE ANGLE }\end{array}$ & $27^{\circ} \pm 5$ & $16^{\circ}$ & $23^{\circ}$ \\
\hline LAFH & $65.6 \pm 4.9 \mathrm{~mm}$ & $60 \mathrm{~mm}$ & $68 \mathrm{~mm}$ \\
\hline FACE HEIGHT RATIO & $62-65 \%$ & $58.8 \%$ & $71.80 \%$ \\
\hline $\begin{array}{l}\text { LOWER INCISOR - } \\
\text { APO UNE }\end{array}$ & $0-2 \mathrm{~mm}$ & $+2.5 \mathrm{~mm}$ & $+5 \mathrm{~mm}$ \\
\hline
\end{tabular}

Fig. 6: Pre and post treatment digital cephalometric reading with superimposition 

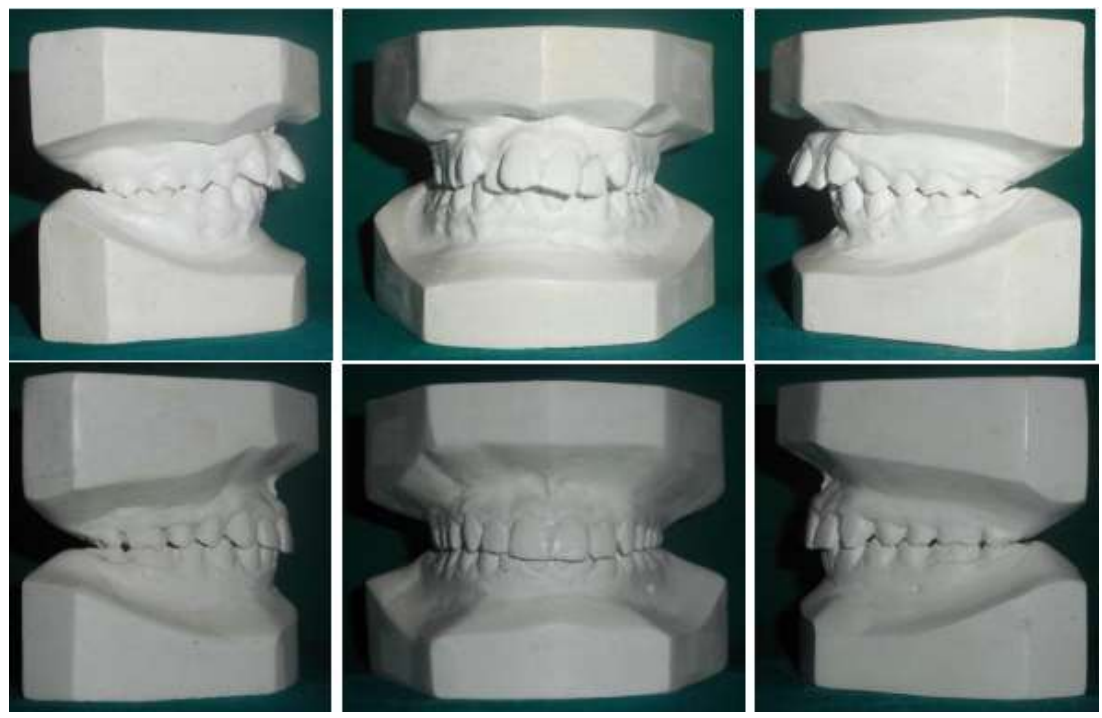

Fig. 7: Pre and post treatment dental models in right, central and left views
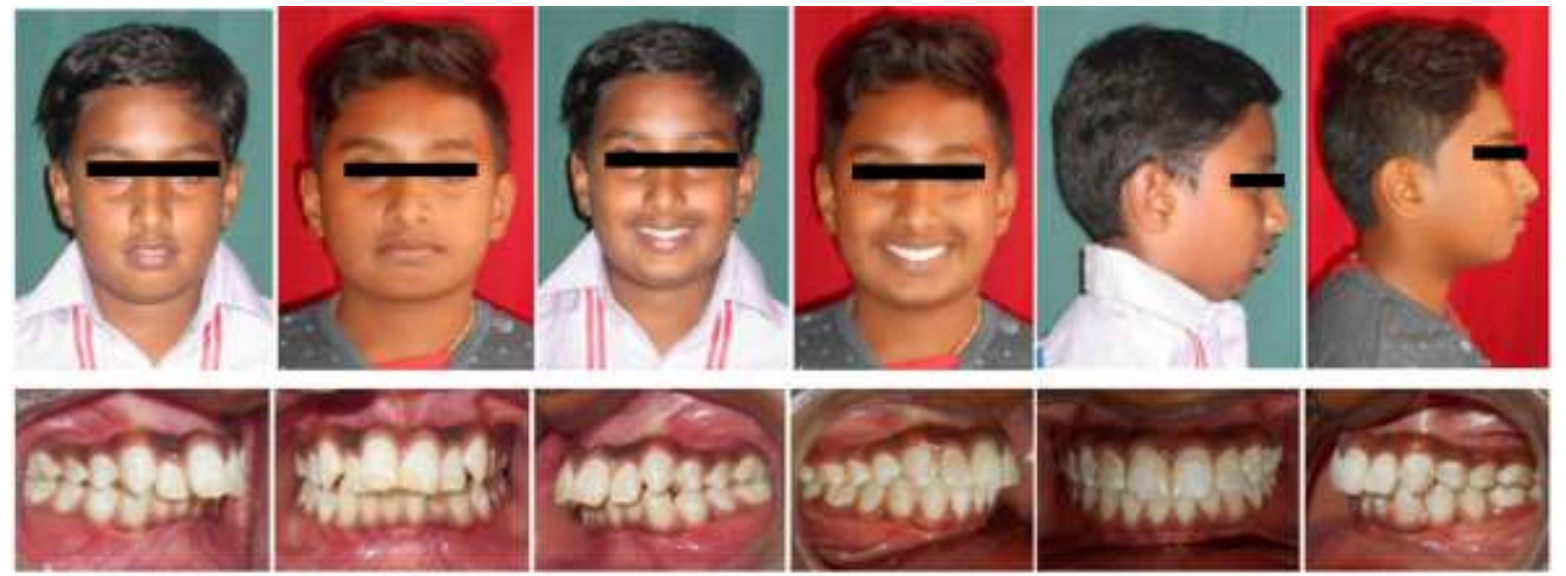

Fig. 8: Comparison of Pre-treatment and Post-treatment extraoral facial photographs and intraoral photographs

\section{Discussion}

Assessment of actual growth in an individual is important as every individual has a different response to different course of treatment, and particularly in orthodontics and dentofacial orthopaedics, it is indicated to deliver exact treatment at exact moment with reliability being mainly on the growth status. Chronological age is a misleading phenomenon as it diverts from the main ideology of physiological or biological age, and in order to predict accuracy it is important to assess maturation of bone from initial stage to progressive stage of maturation using the availability of radiographs (hand wrist, OPG and lateral cephalogram). ${ }^{7}$

Engaging class II elastics to the second molars increases the horizontal or sagittal component of force hence to achieve this attaching an elastic from the erupted second molar to the distal end of the lateral incisor is advisable (Thurow 1970 and Alexander 1986). Class II elastics when employed during accelerated growth period can stimulate growth and is independent of the growth pattern being vertical. ${ }^{8}$
According to a case report by Manni, Lupini and Cozzani, a case of class II division 1 malocclusion having class II canine and molar relation with retrognathic mandible was corrected (26 months) using class II elastics in regard to prominent profile changes and with respect to Sn-PG - 75 degrees to 77 degrees, AN-PG decreased from 6 degrees to 4 degrees in post-treatment values and overjet also decreased significantly from $5.5 \mathrm{~mm}$ to $2.0 \mathrm{~mm}$. ${ }^{9}$ In another case report by Giancotti A et al, in a case of two adolescents, one male and one female in a growing phase having class II division 2 malocclusion were treated with Invisalign treatment technique using class II elastics. In the male patient decreased overjet was seen as upper incisors were in palatal inclination, initial and final cephalometric superimposition in the male patient showed that mandibular position in regard to SN/PG changed from 78 degree to 82 degree and NA/PG sagittal jaw relationship was corrected from 4 degrees to 1 degree, the overbite was reduced from 5 $\mathrm{mm}$ to $2 \mathrm{~mm}$ and overjet from $1 \mathrm{~mm}$ to $0 \mathrm{~mm}$. In the female patient presenting with $4 \mathrm{~mm}$ overbite and palatal inclination of the upper incisors, the initial and final cephalometric superimposition showed mandibular position 
SN/PG changed from 77 to 79 degrees and NA/PG sagittal jaw relationship changed from 3 degrees to 1 degree, overbite was reduced from $4 \mathrm{~mm}$ to $2.5 \mathrm{~mm}$ and overjet from $2 \mathrm{~mm}$ to $1 \mathrm{~mm} .^{10}$

\section{Conclusion}

Achieving skeletal correction of class II malocclusion with retrognathic mandible orthopedically is a challenge which is dependent upon timely diagnosis of the actual growth rate of an adolescent. Lack of literature on the use of class II elastics for correction of skeletal class II malocclusion is suggestive of its lack of usage for growth modification. However, it can be suggested that with continuous use of class II elastics for longer duration and under the influence of heavier forces, orthopaedic changes can be accomplished in order to modify the growth and to bring about significant changes in the profile.

\section{Source of Funding}

None.

\section{Conflict of Interest}

None.

\section{References}

1. Bishara S E. Facial and dental changes in adolescents and their clinical implications. Angle Orthod 2000;70(6):471-83.

2. Carlos F M. Use of skeletal maturation based on hand wrist radiographic analysis as a predictor of facial growth: A systematic review. Angle Orthod 2004;74:118-24.
3. Monica T D A et al. Clinical and radiographic guidelines to predict pubertal growth spurts. Dent Press J Orthod 2011;16(5):98-103.

4. Mark E B. Interarch maxillary molar distalization appliances for class II correction. J Clin Orthod 2008;XLII(1):35-42.

5. Cristina D B. Effect of class II intermaxillary elastics in orthodontic therapy. TMJ 2004;54(4):406-409.

6. Guilherme $\mathrm{J}$ et al. Correction of class II malocclusion with class II elastics: A systematic review. Am J Orthod Dentofacial Orthop 2013;143:383-92.

7. Sushil Kumar. Skeletal maturation evaluation using mandibular second molar calcification stages. Angle Orthod 2012;82:501-6.

8. Aynur Aras. The effect of zigzag elastics in the treatment of class II division 1 maolcclusion with hypo and hyperdivergent growth patterns. A pilot study. Eur J Orthod 2001;23:393-402.

9. Antonio $\mathrm{M}$ et al. Combining skeletal anchorage and intermaxillary elastics in class II malocclusion. J Clin Orthod 2018;LII(4):227-234.

10. Aldo G. Correction of class II malocclusion in growing patients by using the invisalign technique: Rational bases and treatment staging. J Orthod Endod 2017;3(4:12):1-12.

How to cite this article: Trivedi M, Raghunath N, Akasapu A. Correction of skeletal class II malocclusion using class II elastics in an adolescent patient, Indian J Orthod Dentofacial Res 2019;5(3):98-103. 